\title{
IMPLEMENTASi Prinsip Desain ARSITEKTUR BioKLimatik Pada Bangunan PerpustakaAn Di Klaten
}

\author{
Hajar Kusuma Cahyaningrum $^{1^{*}}$, Hardiyati ${ }^{2}$, Rachmadi Nugroho ${ }^{3}$ \\ Program Studi Arsitektur, Fakultas Teknik, Universitas Sebelas Maret Surakarta ${ }^{1}$ \\ Email : hajarkusumac@gmail.com* \\ Program Studi Arsitektur, Fakultas Teknik, Universitas Sebelas Maret Surakarta ${ }^{2}$ \\ Program Studi Arsitektur, Fakultas Teknik, Universitas Sebelas Maret Surakarta ${ }^{3}$
}

\begin{abstract}
Perpustakaan merupakan fasilitas publik yang bertujuan memenuhi kebutuhan akan informasi, sementara kondisi perpustakaan di Kota Klaten kurang mendukung kebutuhan tersebut dikarenakan fasilitas yang tidak memadai. Kajian ini menerapkan kaidah arsitektur bioklimatik pada bangunan perpustakaan sebagai sarana edukatif yang nyaman dengan mempertimbangkan fenomena serta iklim tropis dari Kota Klaten. Metode yang digunakan adalah melakukan kajian literasi terhadap teori yang berkaitan dengan bangunan perpustakaan dan pendekatan arsitektur bioklimatik, selanjutnya mengaplikasikan prinsip desain arsitektur bioklimatik ke dalam proses analisis bangunan berupa pemilihan tapak, penentuan ruang, pengolahan massa bangunan serta tampilan fasad bangunan. Metode aplikasi prinsip desain arsitektur bioklimatik pada bangunan perpustakaan menghasilkan bangunan publik sarana edukatif yang nyaman, hemat energi, ramah lingkungan serta dapat mengoptimalkan keadaan iklim sekitar bangunan dengan fungsi sebagai pemenuh kebutuhan informasi.
\end{abstract}

Keywords : library, public building, bioclimatic architecture.

\section{PENDAHULUAN}

Perpustakaan merupakan unit kerja dari suatu badan atau lembaga tertentu yang mengelola bahan - bahan pustaka. Baik berupa buku maupun non buku yang diatur secara sistematis menurut aturan tertentu sehingga dapat digunakan sebagai sumber informasi. (Suhendar, 2005:3) Perpustakaan berdasarkan UU No. 43 Tahun 2007 adalah institusi pengelola koleksi karya tulis, karya cetak, dan/atau karya rekam secara profesional dengan sistem yang baku guna memenuhi kebutuhan pendidikan, penelitian, pelestarian, informasi, dan rekreasi para pemustaka.

Perpustakaan mencakup suatu ruangan, bagian dari gedung/bangunan atau gedung tersendiri yang berisi buku - buku koleksi, yang diatur dan disusun demikian rupa, sehingga mudah untuk dicari dan dipergunakan apabila sewaktu - waktu diperlukan oleh pembaca. (Sutarno, 2006)
Fenomena umum tentang perpustakaan adalah rendahnya minat baca dan daya beli. Selain itu adalah keterbatasan teknologi dalam mengakses suatu situs, keterbatasan anggaran daerah untuk perpustakaan, serta perpustakaan dianggap sebagai tempat yang membosankan dan tidak nyaman.

Kota Klaten merupakan salah satu kota budaya di Propinsi Jawa Tengah yang sedang berkembang, memiliki satu perpustakaan daerah resmi yaitu Kantor Arsip dan Perpustakaan Kabupaten Klaten namun masih minim dari segi arsitektural, kenyamanan pengguna dan pelayanannya.

Media distribusi pustaka di perpustakaan Klaten masih belum mencukupi kebutuhan dan kurang lengkap, sedangkan kelancaran distribusi memiliki peran penting dalam hubungannya mensukseskan gerakan gemar membaca. Faktor lainnya yang tak kalah penting adalah cukup banyak jumlah instansi pendidikan di Kota Klaten. Faktor instansi 
pendidikan ini berkaitan dengan potensi layanan perpustakaan ke depannya.

Dengan kondisi - kondisi tersebut di atas maka potensi pengembangan perpustakaan sebagai sebuah fasilitas yang menunjang kegiatan dari instansi - instansi tersebut adalah besar dan sangat dimungkinkan. Selain bersifat edukatif, perpustakaan Kota Klaten yang direncanakan diharapkan nyaman dan rekreatif sehingga menarik perhatian pengunjung baik dari dalam maupun luar kota terhadap fasilitas - fasilitas yang telah disediakan.

Kota Klaten dikenal memiliki iklim tropis dan bersuhu panas. Dengan semakin padatnya lahan ditutupi oleh bangunan serta semakin minimnya ruang terbuka hijau dapat semakin meningkatkan kenaikan suhu di Kota Klaten.

Untuk mengatasi permasalahan tersebut maka diperlukan beberapa inovasi baru dalam bidang arsitektur untuk merancang bangunan yang tanggap terhadap iklim dan lingkungan kota, salah satunya ialah pendekatan bioklimatik. Arsitektur bioklimatik menekankan rancangan bangunan dengan memanfaatkan secara maksimal iklim kota serta mengoptimalkan hasil energi pasif pada bangunan.

Perpustakaan dengan Pendekatan Arsitektur Bioklimatik di Klaten merupakan sebuah bangunan publik yang menyediakan fasilitas pencarian informasi dengan berbagai penunjang, juga sebagai sarana pendidikan guna memperoleh ilmu pengetahuan bagi para pemustaka di Kota Klaten.

Bioklimatik berasal kata bioclimatology. Menurut Kenneth Yeang (1994), "Bioclimatology is the study of the relationship between climate and life, particulary the effect of climate on the health of activity of living things."

Arsitektur bioklimatik merupakan seni merancang bangunan dengan metode hemat energi yang memperhatikan iklim setempat dan memecahkan masalah iklim dengan menerapkannya pada elemen bangunan. (Rosang:2016)

Secara umum, prinsip desain bioklimatik adalah: hemat energi (Conserving Energy), memperhatikan kondisi iklim (Working with Climate), ramah lingkungan (Minimizing New
Resources), merespon keadaan tapak dari bangunan (Respect for tapak), dan nyaman bagi penghuni bangunan tersebut (Respect for user). Kelima prinsip dasar arsitektur bioklimatik tersebut kemudian disederhanakan kembali menjadi tiga prinsip desain arsitektur bioklimatik yaitu hemat energi, memperhatikan kondisi iklim, dan ramah lingkungan.

\section{METODE}

Objek desain rancangan Perpustakaan ini menggunakan pendekatan arsitektur bioklimatik. Metode perancangan perpustakaan diawali dengan melakukan studi empiris pada perpustakaan yang telah ada guna mendapatkan pola aktivitas dan kebutuhan ruang. Langkah kedua adalah dengan proses literasi terhadap teori arsitektur bioklimatik.

Setelah mendapatkan intisari dari tema yang diangkat, kemudian merencanakana aktivitas dan kebutuhan ruang berdasarkan kebutuhan perpustakaan.

Langkah selanjutnya adalah menguraikan pendekatan arsitektur bioklimatik. Arsitektur bioklimatik memberikan penyelesaian desain pada bangunan dengan memperhatikan hubungan antara bentuk arsitektur dengan lingkungan (iklim) daerah tersebut. Pengaplikasian tiga prinsip dasar arsitektur bioklimatik yang telah dirumuskan .

Hemat energi dengan penggunaan material bangunan yang dapat mereduksi panas dan suara, serta pemanfaatan energi alami secara maksimal.Penyesuaian iklim dengan menambahkan beberap vegetasi dan mengolah ruang terbuka hijau secara maksimal.

Ramah lingkungan dengan memanfaatkan sumber daya alam yang telah tersedia di sekitar tapak, dan menggunakan material bangunan yang ramah lingkungan.

\section{HASIL DAN PEMBAHASAN}

Berdasarkan karakter pengguna, aktivitas pengguna, dan peningkatan jumlah bahan koleksi hingga 20 tahun ke depan, diperoleh total luas ruang yang dibutuhkan 5.873,25 $\mathrm{m}^{2}$ dengan rincian zona umum : $970 \mathrm{~m}^{2}$, zona 
perpustakaan : $1.688,75 \mathrm{~m}^{2}$, zona pengelola : $810,6 \mathrm{~m}^{2}$, zona penunjang : $1.724,5 \mathrm{~m}^{2}$, zona servis : $679,4 \mathrm{~m}^{2}$

Tabel 1. Analisis Kebutuhan Ruang

\begin{tabular}{|c|c|}
\hline $\begin{array}{l}\text { KELOMPOK } \\
\text { KEGIATAN }\end{array}$ & KEBUTUHAN RUANG \\
\hline Kegiatan Zona Umum & $\begin{array}{l}\text { In - out gate } \\
\text { Parkir } \\
\text { Main lobby }\end{array}$ \\
\hline $\begin{array}{l}\text { Kegiatan Zona } \\
\text { Perpustakaan }\end{array}$ & $\begin{array}{l}\text { Pelayanan umum } \\
\text { Pelayanan koleksi } \\
\text { remaja/dewasa } \\
\text { Mini Bioskop } \\
\text { Pelayanan periodikal } \\
\text { Pelayanan referensi } \\
\text { Pelayanan koleksi anak- } \\
\text { anak }\end{array}$ \\
\hline $\begin{array}{l}\text { Kegiatan Zona } \\
\text { Pengelola }\end{array}$ & $\begin{array}{l}\text { Direktur } \\
\text { Subbid TU/Administrasi } \\
\text { Pengolahan dan pengadaan } \\
\text { bahan pustaka } \\
\text { Pustakawan } \\
\text { Layanan pustaka } \\
\text { Engineering } \\
\text { Keamanan } \\
\text { Sales \& marketing } \\
\end{array}$ \\
\hline $\begin{array}{l}\text { Kegiatan Zona } \\
\text { Penunjang }\end{array}$ & $\begin{array}{l}\text { PP IPTEK } \\
\text { R. Seminar } \\
\text { Exhibition hall } \\
\text { R. Pertunjukkan outdoor } \\
\text { Bookstore } \\
\text { Retailshop } \\
\text { Cafe baca } \\
\text { Taman baca } \\
\end{array}$ \\
\hline Kegiatan Zona Servis & $\begin{array}{l}\text { Masjid } \\
\text { Lavatory } \\
\text { Patry } \\
\text { Gudang } \\
\text { Loading dock } \\
\text { Utilitas }\end{array}$ \\
\hline
\end{tabular}

Pemilihan tapak mempertimbangkan aspek hemat energi, kondisi iklim, lingkungan, dan wilayah PKW.

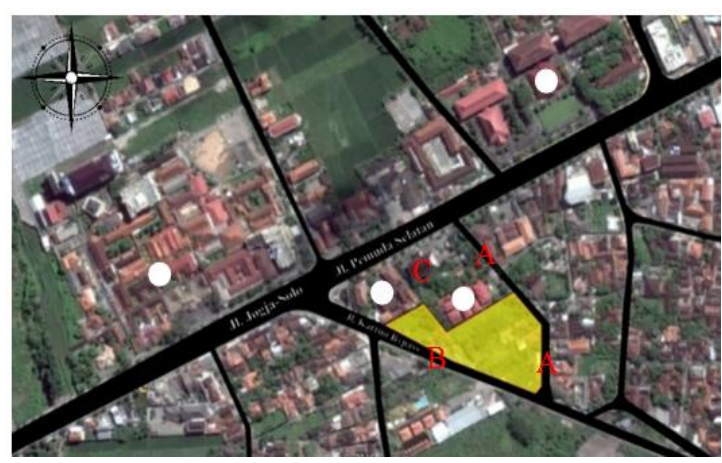

Gambar 1. Lokasi tapak terpilih
Tapak yang terpilih berada di Kecamatan Klaten Selatan, strategis dan mudah dalam hal pencapaian dari luar tapak dikarenakan jalan ini merupakan jalan lalu lintas utama yang dilewati kendaraan umum dari/menuju ke luar kota. Hal ini merupakan salah satu pengaplikasian prinsip 'hemat energi' pada lokasi tapak. Pemilihan ME/SE menerapkan prinsip desain 'ramah lingkungan', penempatan entrance yang tepat dapat membantu kenyamanan pengguna baik dari dalam maupun luar bangunan (meminimalisir terjadinya cross circulation).

Konsep hemat energi dalam mereduksi penggunaan energi pada bangunan berupa pengkondisian bangunan terhadap iklim setempat agar terasa nyaman dengan cara mensinergikan bangunan dengan keadaan iklim setempat dan pemanfaatan potensi iklim tersebut pada bangunan yang direncanakan.

Bangunan perpustakaan sebagai bangunan dengan fungsi edukatif membutuhkan ketenangan dan kenyamanan. Dengan memaksimalkan ruang terbuka hijau pada zona publik dari tapak merupakan salah satu penerapan dari prinsip desain 'hemat energi dan ramah lingkungan'. RTH dengan beberapa vegetasi di dalamnya dapat membantu reduksi panas dan bising yang akan masuk ke dalam bangunan, selain itu juga dengan memanfaatkan vegetasi yang sudah ada di dalam tapak (tidak merusak SDA yang ada).

Pemilihan bentuk massa bangunan perpustakaan ini menitikberatkan pada kemudahan pola pengaturan sirkulasi/ konfigurasi rak buku di dalamnya. Oleh karenanya bentuk massa dasar yang dapat mengakomodasi kebutuhan ruang dalam bangunan perpustakaan adalah bentuk persegi. Bentuknya yang stabil dan statis sama halnya dengan bangunan perpustakaan yang bersifat edukatif dan mengedepankan kenyamanan bangunan. Massa bangunan perpustakaan diolah dalam tapak dengan mempertimbangkan pencapaian, view, orientasi, klimatologi, serta kebisingan. 


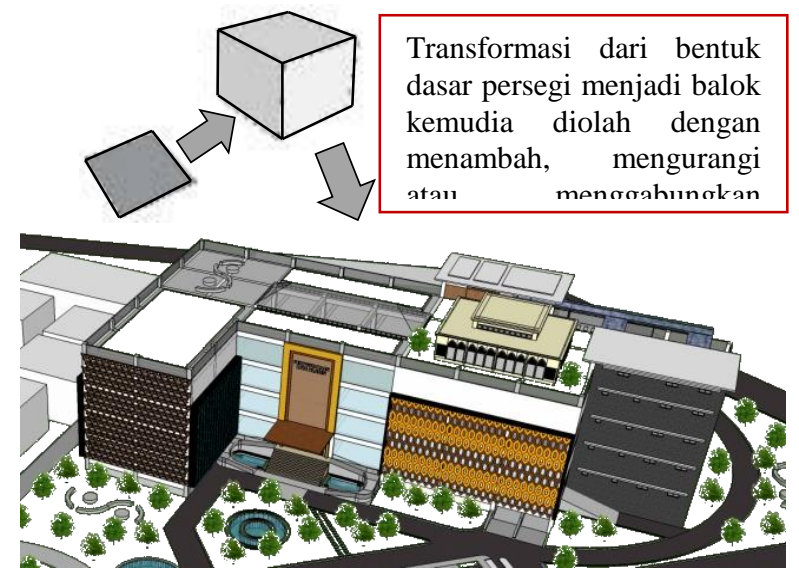

Gambar 2. Gubahan massa bangunan

Tata massa bangunan berdasar pada prinsip arsitektur bioklimatik dengan mempertimbangan arah mata angin yang berpengaruh pada panjang dan lebar bangunan serta letak bukaan pada bangunan. Pengolahan ruang tebuka hijau pada sekeliling bangunan dilakukan dengan maksimal guna mewujudkan aplikasi dari prinsip arsitektur bioklimatikk itu sendiri.

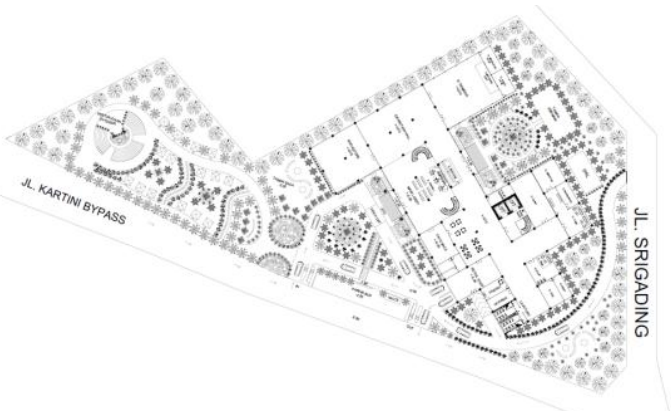

Gambar 3. Siteplan

Penerapan hemat energi, ramah lingkungan dan menyesuaikan iklim pada penggunaan material, warna, petunjuk/tanda, penghawaan, pencahayaan, serta aksesibilitas bangunan.

Tampilan bangunan berpengaruh pada besar kecilnya pencahayaan dan penghawaan yang masuk ke dalam bangunan. Dengan menggunakan material kaca di setiap ruang perpustakaan bertujuan agar pencahayaan yang masuk dapat secara maksimal. Penggunaan kaca juga digunakan pada skylight yang berada tepat di tengah bangunan agar meminimalisir penggunaan energi listrik pada siang hari. Peletakan secondary skin yang berguna mereduksi panas yang masuk ke dalam bangunan pada dinding bangunan yang bermaterialkan kaca.

Selain itu, penggunaan ekspos batu alam dan batu bata ringan pada ruangan pengelola dan servis juga bertujuan sebagai maintenance bangunan.

Penggunaan bahan - bahan bangunan yang ramah lingkungan dan dapat dimanfaatkan kembali. Penggunaan material kaca pada beberapa bagian dinding bangunan perpustakaan yang bertujuan untuk menghemat penggunaan listrik dari segi pencahayaan.

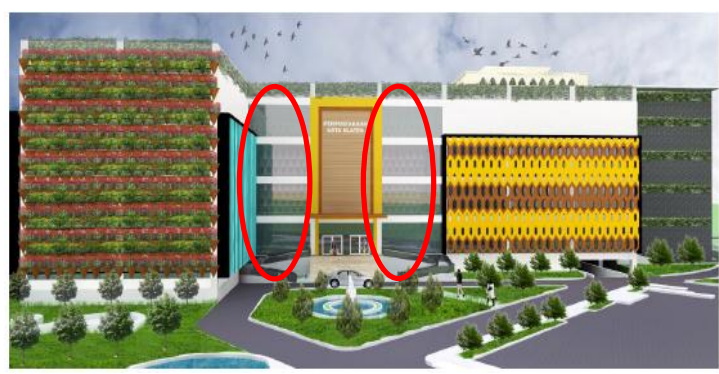

Gambar 4. Aplikasi material kaca pada dinding

Pelapisan dinding bangunan curtain wall menggunakan aluminium yang berfungsi sebagai $U V$ protector.

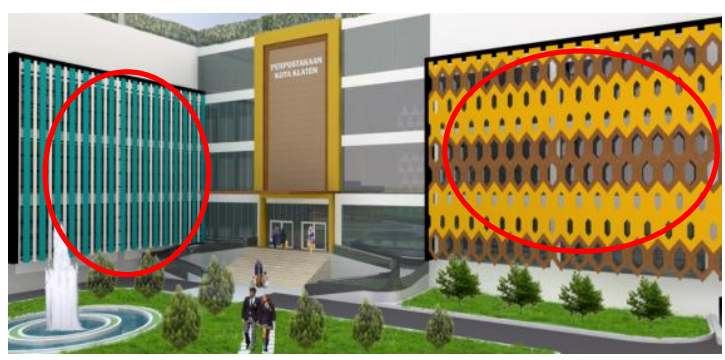

Gambar 5. Aplikasi curtain wall

Penggunaan roof garden yang berfungsi sebagai proses pendingin ruangan alami. Penggunaan vegetasi berupa tanaman rindang yang mengelilingi bangunan. Vegetasi ini juga dapat berfungsi sebagai reduksi kebisingan.

Pemaksimalan lahan terbuka hijau yang dimanfaatkan sebagai taman baca (outdoor) berfungsi sebagai reduksi panas dan reduksi kebisingan yang berasal dari luar bangunan. 
Pemanfaatan grey/black water yang telah diolah di IPAL untuk digunakan kembali pada closet dan menyirami tanaman baik pada taman baca maupun roof garden juga untuk mengairi tanaman hydrophonic yang digunakan sebagai secondary skin pada fasad bangunan.

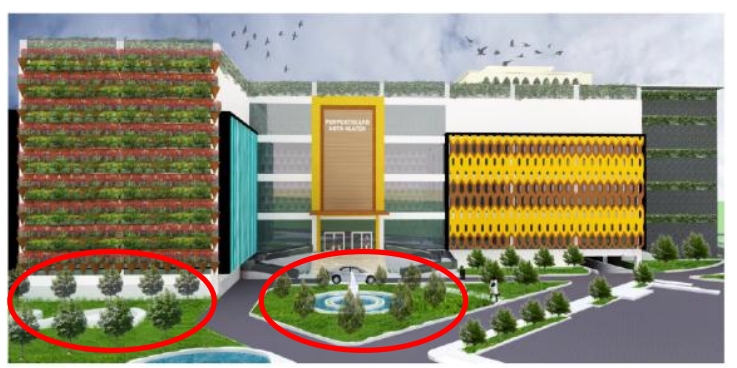

Gambar 6. Vegetasi

Warna yang dipilih untuk sebuah ruang sesuai dengan jiwa pemustaka. Ruang perpustakaan (ruang koleksi) dapat menggunakan warna warna netral serta warna - warna alami kayu untuk sebagian ruang atau perabot.

Perbedaan warna dapat menjadi penanda batas ruang satu dengan yang lain. Petunjuk/tanda merupakan salah satu elemen yang penting dan perlu direncanakan dengan baik agar memudahkan pemustaka dalam memanfaatkan fasilitas di dalam bangunan perpustakaan. Petunjuk/tanda dapat berupa identitas bangunan pada tampilan fisik luar bangunan guna mempermudah pengunjung mencari perpustakaan ini.

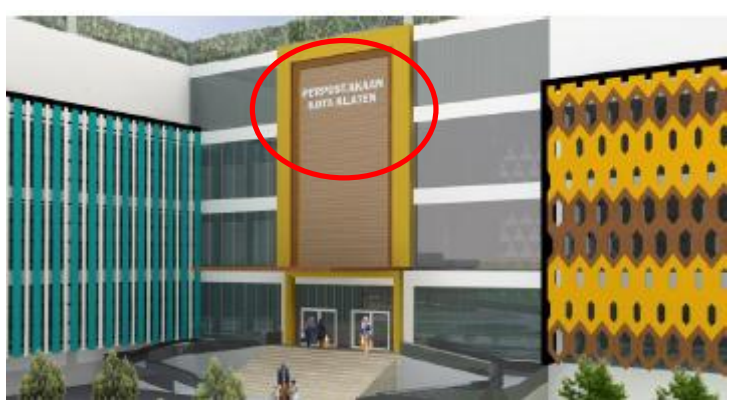

Gambar 7. Identitas bangunan

Suhu ideal ruang perpustakaan a $20^{\circ} \mathrm{C}-24^{\circ} \mathrm{C}$ dengan kelembaban berkisar $40 \%$ - $60 \%$. sangat sulit dicapai pada iklim tropis di Indonesia hanya dengan mengandalkan pengudaraan alami. Pengudaraan buatan (seperti : AC) dapat diterapkan untuk mencapai kenyamanan pengudaraan ruang bagi pemustaka di dalam ruangan.

Penghawaan alami dapat diupayakan melalui bukaan jendela atau lubang ventilasi yang memadai.

Pencahayaan yang merata pada seluruh area, baik pada area koleksi maupun pada area membaca. Pencahayaan minimum untuk ruang perpustakaan adalah sekitar 200 lux. Pencahayaan menggunakan jenis lampu TL dan lampu hemat energi, diatur sedemikian rupa agar tidak terjadi 'glare' atau silau yang mengganggu kenyamanan pengguna.

Selain itu ruang perpustakaan harus dapat dicapai dengan mudah oleh seluruh pengguna juga kaum disabilitas.

\section{KESIMPULAN}

Penerapan arsitektur bioklimatik sebagai strategi perancangan menjadi sangat tepat diterapkan dalam perancangan perpustakaan di Klaten agar memaksimalkan fungsi edukatif, nyaman dan rekreatif sehingga menarik perhatian pengunjung baik dari dalam maupun luar kota terhadap fasilitas - fasilitas yang telah disediakan.

Penerapan tiga prinsip desain arsitektur bioklimatik yaitu hemat energi, memperhatikan kondisi iklim, dan ramah lingkungan pada aspek-aspek fisik ruang dapat menciptakan ruang yang lebih nyaman.

\section{REFERENCES}

Depdikbud. 1994. Kamus Besar Bahasa Indonesia. Jakarta: Balai Pustaka.

Rosang, Agnes Glorya Pretty. 2016. Penerapan Konsep Desain Arsitektur Bioklimatik.

Sutarno, NS. 2006. Perpustakaan dan Masyarakat. Ed. Rev. Jakarta : Sagung Seto.

Yeang, Ken. 1994, Bioclimatic skyscrapers, London: Artemis. 